\title{
La nación en la España del siglo XXI: Un debate inacabable
}

\author{
Xosé M. Núñez Seixas
}

\section{UN VIEJO DEBATE}

A lo largo de la primera década del siglo XXI, la cuestión territorial ha vuelto a situarse en los lugares principales de la agenda política española. Son tiempos de reforma de los Estatutos de Autonomía, de replanteamiento de la cuestión nacional, y de lamentos catastrofistas por parte de diversas tribunas mediáticas sobre la posible desmembración de España.

Sin embargo, no nos hallamos ante nada sustancialmente nuevo. Pues el pleito nacional ha jugado un papel protagonista en la Historia contemporánea española desde la primera década del siglo XX, durante la Restauración, la II República, la Guerra Civil y, de modo soterrado, durante el Franquismo. Desde principios de la década de 1970, la articulación territorial del Estado se ha convertido también en una de las cuestiones más importantes que han sido objeto de discusión durante el proceso de Transición y consolidación democrática. La Constitución de 1978 parecía haber resuelto el problema, al menos en apariencia: España era definida como una única nación, y por lo tanto como único titular de la soberanía, pero el derecho a la autonomía de las «regiones y nacionalidades» era igualmente sancionado en términos normativos. Desde entonces y hasta hoy, la España democrática ha experimentado una notable transformación de su estructura territorial, que la ha llevado a convertirse en uno de los Estados más descentralizados de Europa y del mundo. Casi un 55 por ciento del presupuesto público del Estado es gestionado en la actualidad por las 17 Comunidades Autónomas. Además, se trata de una autonomía regional no sólo administrativa, sino también política y legislativa. Y, en algunos casos (Navarra y Comunidad Autónoma Vasca), es también una plena autonomía financiera. 
El debate tampoco es tan nuevo desde la perspectiva de los últimos veinticinco años. Pues el problema - encajar la plurinacionalidad del Estado en una fórmula mononacional del mismo- estaba contenido dialécticamente en la solución. La solución constitucional de 1978, en un principio, no era plenamente satisfactoria para casi nadie. Se trataba de un pacto entre actores diversos, como en otros aspectos de la Carta Magna. Pero la definición territorial de España, y de España como nación, fue el campo en el que el acuerdo resultó más laborioso, y que consumió buena parte de las energías de la Comisión Constituyente, como después recordaron varios ponentes de la Carta Magna (Solé Tura, 1985; Bastida, 1998). Por un lado, los nacionalismos sin Estado (catalán, vasco, pero también con fuerza inferior el gallego) no aceptaron de modo unánime la solución de 1978. Su objetivo era y sigue siendo, ayer como hoy, la transformación de España en un Estado plurinacional, en el que las auténticas naciones (España o Castilla, Galicia, Cataluña o los Países Catalanes, y el País Vasco comprendiendo a Navarra y eventualmente los territorios vascos de Francia) deberían ser sujetos soberanos que decidiesen libremente el conformar un Estado (con)federal y plurinacional, o eventualmente seguir su propio camino como entidades políticas independientes. Por lo tanto, cualquier solución político-jurídica que estableciese que España seguía siendo una nación -y la única nación, es decir, el único ente titular en exclusiva de la soberanía- no podía ser aceptada, por presupuestos doctrinales, por parte de los nacionalismos subestatales. Los sectores de los mismos que podríamos denominar más pragmáticos, particularmente el catalanismo mayoritario (Convergència i Unió [CiU] de modo afirmativo, el Partido Nacionalista Vasco [PNV] de modo menos convencido) aceptaron o acataron la solución constitucional y asumieron que la autonomía podía ser vista como un primer paso en la conquista sucesiva de mayores cotas de autogobierno, que en un futuro podría reconfigurarse de modo más cercano a su objetivo último. ¿Cuál era este objetivo lejano? Aunque éste siempre quedaba un tanto en la penumbra, bien podía consistir en una independencia más o menos formal o más o menos simbólica en el contexto del proceso de unificación europea, bien un nivel considerado «suficiente» de autogobierno soberano en el seno de un Estado español que asumiese una articulación que garantizase su carácter plurinacional y, por lo tanto, reconociese la existencia de una asimetría simbólica y de poder entre sus diferentes territorios.

Había dos aspectos de gran relevancia. Primero, el hecho de que la Constitución de 1978 sancionase la existencia de una asimetría de hecho y de derecho entre «nacionalidades» y regiones. Algo que, a pesar de su indefinición -pues la Carta Magna no especifica en su texto cuáles son las regiones y cuáles las nacionalidades, y menos aún en qué consiste la diferencia entre unas y otras-, fue 
contemplado como un reconocimiento en potencia, o al menos simbólico, de la plurinacionalidad del Estado democrático. Era posible, por lo tanto, profundizar en esa distinción entre regiones y nacionalidades a partir de lo ya establecido en la Constitución, sin romper sus límites pero ensanchando sus moldes, gracias a interpretaciones jurídicas flexibles del Título VIII de la misma. En segundo lugar, la Constitución de 1978 también reconoce en su Disposición Transitoria Adicional 2. ${ }^{a}$ los «derechos históricos»-es decir, implícitamente preconstitucionales- de los territorios vascos y navarros, y por lo tanto a partir de ese reconocimiento sería posible también desarrollar interpretaciones ulteriores de tales derechos históricos (que al ser así formulados adquirían una suerte de derecho de preeminencia respecto a la propia Constitución). De este modo, tanto el PNV como CiU y, a partir de mediados de la década de 1990, el Bloque Nacionalista Galego (BNG), aspiraron a jugar pragmáticamente con la posibilidad de reformar la Constitución para avanzar en la profundización y ampliación del autogobierno de sus respectivos territorios o naciones putativas, contemplando esa reforma como un paso adelante en el reconocimiento de la plurinacionalidad del Estado.

Otro sector, más minoritario pero social y políticamente significativo, de los movimientos nacionalistas subestatales se negó desde un principio a aceptar jugar dentro de la nueva estructura de oportunidades que ofrecía la articulación del Estado de las Autonomías. Algunos de esos sectores - el nacionalismo radical vasco, ligado en buena medida en la esfera política a la organización terrorista ETA — rechazaron hasta hoy, salvo breves intervalos, la participación en la dinámica institucional, y han generado una cultura política de deslegitimación y oposición frontal al Estado democrático español, visto como simple heredero del franquismo. Otras tendencias aceptaron más o menos pragmáticamente que el jugar dentro del campo institucional, aun defendiendo su superación y sustitución por otro totalmente diferente, podía suponer el acumular fuerzas para la consecución en el futuro de una independencia más o menos formal por vías plenamente democráticas. Ha sido el caso de Esquerra Republicana de Catalunya (ERC), también de Eusko Alkartasuna [EA] y sus sucesivas ramificaciones y, con matices, del BNG (Quintana Garrido, 2010).

Por otro lado, un sector importante de los partidos y de la opinión pública española no vio desde un principio con buenos ojos la transformación de España en un Estado descentralizado con amplias dosis de regionalización político-administrativa. Particularmente la Alianza Popular (AP) de Manuel Fraga, pero también algunos sectores de la izquierda estatal, veían en un potencial debilitamiento del Estado y en el propio reconocimiento nominal del término «nacionalidad» en la Carta Magna riesgo para el futuro en lo que respectaba a la integridad del Estado, a la unidad de España. Empero, a medio y largo plazo, 
ambos sectores acabaron por aceptar plenamente la realidad del Estado autonómico, en parte por haber accedido al Gobierno de numerosas Comunidades Autónomas y haber gozado de las ventajas políticas que también concede la descentralización del Estado, como era el disponer de recursos y poder a escala mesoterritorial. Rechazan sin embargo ir más allá de lo legalmente reconocido en 1978 y avanzar, reformar o profundizar en una interpretación federalizante, y no digamos asimétrica, del sistema autonómico puesto en marcha desde 1978. Y desde mediados de la primera década del siglo XXI han abrazado la teoría del adelgazamiento funcional del Estado de las Autonomías, considerado responsable de despilfarrar los recursos públicos y de atentar contra los cimientos de la soberanía de la nación española.

Además, el alma de una buena parte de la izquierda seguía siendo federalista. El problema, en este sentido, radicaba y radica en un punto: ¿Qué tipo de federación? ¿Simétrica o asimétrica, que reconozca la diferencia de las naciones o nacionalidades, o que sea igual para todos, reconociendo 17 Estados federados donde antes había 17 autonomías? ¿Un modelo como el Canadá, como los Estados Unidos, o como Alemania? ¿O bien una recreación de una monarquía federal y plurinacional, al estilo -idealizado- de Austria-Hungría en el pasado? Existen diversos modelos de federalismo y de Estado federal. Y una política de descentralización no es necesariamente sinónima de una cultura de la cooperación federal, ni tampoco de una política del reconocimiento de la diferencia etnocultural y/o nacional. Se trata de niveles diferentes, aunque a menudo se confundan y mezclen en el debate público, e incluso en el lenguaje político.

\section{UNA SOLUCIÓN PERMANENTEMENTE PROVISIONAL}

El desarrollo del Estado de las Autonomías ha tenido el innegable efecto de consolidar lo que podríamos denominar una cultura política de la descentralización (Kraus, 1996; Aja, 1999). Y una cultura política que también admite, o al menos tolera, como valor constitutivo de la identidad española la existencia de una pluralidad etnocultural, institucional e identitaria interna, aunque los límites de ese reconocimiento son muy variables, y pueden oscilar desde el pseudofolclorismo arcaizante hasta el monolingüismo territorial exclusivo. La autonomía y su ejercicio práctico, así como las ventajas asociadas a la descentralización política y administrativa, incluida la amplia expansión de gasto y empleo público durante el período 1980-1995, convenció rápidamente a los ciudadanos de su utilidad, como muestran reiteradamente los sondeos de opinión: las autonomías han creado capital social y potencial de desarrollo y profundización del bienestar (Mota-Consejero, 1998, 2008).

La experiencia del Estado de las Autonomías fue igualmente capaz de con- 
vencer a la derecha española de algunas de sus virtualidades, y la llevó a una aceptación progresiva del sistema autonómico. También hizo a la derecha española, o al menos a sectores importantes de la misma, más sensible hacia la diversidad (política, institucional y cultural) a lo largo de las décadas de 1980 y 1990. La conversión del antiguo ministro de Información y Turismo del régimen franquista, Manuel Fraga Iribarne, en un adalid del regionalismo sano y de la profundización del Estado autonómico durante su larga etapa como presidente de la Comunidad Autónoma (y nacionalidad histórica) de Galicia (1990-2005) fue un buen ejemplo de esa dinámica. Pero también lo fue la presión de las organizaciones territoriales del Partido Popular en Galicia o las Islas Baleares para que se mantuviese un principio de igualdad con los niveles de autogobierno logrados por Cataluña, así como su asunción de un regionalismo más o menos folclórico, pero que no hace ascos de la afirmación etnolingüística de las peculiaridades culturales de ambas comunidades.

No obstante, también son de señalar cuatro fenómenos sustancialmente nuevos, que acompañaron a la consolidación del Estado autonómico:

1. El progresivo convencimiento de que era necesaria una adaptación del Estado de las Autonomías a la nueva realidad institucional europea, creada tras la incorporación de España a la CEE/UE en 1986. Proceso que fue acompañado de la constatación de algunos problemas estructurales en el funcionamiento del Estado autonómico, derivados en parte de los flecos pendientes de resolución en 1978: la cuestión de la financiación de las Autonomías (las Comunidades Autónomas gastaban, pero no recaudaban autónomamente, lo que provocaba que hasta principios de la década de 1990 la tendencia de los gobiernos regionales fuese a gastar más de lo que ingresaban por transferencia del Estado, con generoso recurso a la Deuda Pública); el poco relevante funcionamiento del Senado, una institución prácticamente inane en el sistema parlamentario español, que no cumple la función de Cámara de representación territorial; el fracaso o incompleto desarrollo del carácter multilateral del funcionamiento político del sistema autonómico, afectado por una perversión creciente en su dinámica político-institucional, pues la bilateralidad es más eficiente para los gobiernos regionales que los foros colectivos, a la hora de negociar con el Gobierno central. Ese carácter bilateral se ve además reforzado y condicionado por la coyuntura política: el peso de las minorías parlamentarias nacionalistas o regionalistas a la hora de conformar mayorías estables de apoyo al Gobierno de Madrid influyen en las cesiones de competencias o en la fijación progresiva de porcentajes de recaudación fiscal para los gobiernos autónomos.

Todo ello se tradujo también, al menos hasta mediados de la década de 1990, en un alto grado de conflictividad legislativa entre el Gobierno central y 
los gobiernos autónomos, como ponía de relieve el alto número de leyes autonómicas recurridas por el Gobierno central ante el Tribunal Constitucional. El Estado de las Autonomías parecía un sistema permanentemente abierto y sometido a múltiples y circunstanciales parcheados. Una duradera solución provisional, pero útil, que conseguía funcionar, mediante un modelo de competencia múltiple etnoterritorial; pero cuyas deficiencias parecían convertirse en crónicas (Moreno, 1997; Beramendi y Máiz, 2003).

2. La autonomía también creó autonomistas allí donde no los había, o había más bien pocos, en 1975-78 (García Álvarez, 2002). Proceso que se ha registrado tanto en las islas Canarias como en Aragón, Andalucía, Cantabria o Valencia. No es de extrañar, dado que la configuración de una estructura administrativa y política descentralizada abrió perspectivas inesperadas para un buen número de elites locales: parlamentos y asambleas regionales, cuando no insulares y hasta comarcales; multiplicación de cargos políticos, recursos y cargos administrativos; asignación de presupuestos y creación, en suma, de esferas de poder (y de configuración de clientelas políticas) a escala mesoterritorial antes inexistentes. Este proceso contribuyó a crear una ventana de oportunidades, en términos politológicos.

Después de que Unión de Centro Democrático (UCD) se resquebrajase en 1982, muchos grupos de notables y elites políticas locales de tendencia más o menos conservadora y pragmática se unieron a partidos y plataformas regionalistas preexistentes, o bien fundaron organizaciones de ese carácter de nuevo cuño. Algunos de ellos consiguieron consolidarse electoralmente y pervivir hasta el día de hoy, detentando el poder en varias Comunidades Autónomas en solitario o en coalición de gobierno con partidos estatales. Éste fue el caso de Unión del Pueblo Navarro, del Partido Aragonés, del Partido Regionalista de Cantabria, de Unión Valenciana o de Coalición Canaria. No son, pese a las apariencias, partidos o movimientos que estén imbuidos de un credo nacionalista subestatal, aunque algunos de sus sectores integrantes (como en el caso canario) sí tengan ese carácter. Su límite reivindicativo se sitúa un paso antes de la autodeterminación, postulado que jamás afirman. Pero su estrategia política consiste, de modo resumido, en una dinámica de imitación y reacción respecto a los gobiernos nacionalistas de Cataluña y el País Vasco: conseguir siempre el mismo nivel de autogobierno que alcancen las «nacionalidades históricas», y equipararse en rango estatutario a ellas. De hecho, a lo largo de la década de 1990 tanto Aragón como Canarias y la Comunidad Valenciana se autoproclamaron «nacionalidades históricas» en sus Estatutos de Autonomía, aun si tal meta era vista, paradójicamente, como una garantía de que sus territorios seguirían siendo considerados entre los ciudadanos «de primera clase» de España. Dicho de otro modo: para 
ser el primero de los españoles, era necesario ser una nacionalidad histórica (Núñez Seixas, 2005b).

3. La tendencia a la igualación competencial de todas las Comunidades Autónomas también contribuyó a generar el efecto contrario: la insatisfacción permanente de los nacionalismos subestatales, incluso de sus sectores más pragmáticos, ante un sistema territorial que tendía a confundir sus naciones con otros territorios considerados meras regiones, y en el que las elites del Estado central no siempre eran propensas a operar las transferencias de competencias con la generosidad y la rapidez que las nuevas elites periféricas deseaban (Genieys, 1997). Tanto los nacionalistas catalanes como los vascos y gallegos llegaron a dos conclusiones desde finales de la década de 1980:

a) El ejercicio de la autonomía política ha contribuido a reforzar los referentes de identidad mesoterritoriales en las nacionalidades históricas, pero no ha vigorizado de modo sustancial, o al menos no en la medida en que muchos pretendían, el polo de las identidades nacionales excluyentes en sus territorios, es decir, la consolidación de identidades plenamente nacionales alternativas a la española y hegemónicas socialmente. Por el contrario, en las periferias nacionalistas sigue prevaleciendo hasta el día de hoy un sentimiento de doble identidad entre los ciudadanos, con mayores o menores pesos del polo español o periférico (es decir, más o menos español que vasco, gallego o catalán, además de tan español como vasco, gallego o catalán), aun con las debidas particularidades de cada caso. Aunque es cierto que desde 2005 se ha registrado un incremento del sentimiento independentista en Cataluña, por ejemplo, la identidad dual sigue siendo predominante en ese territorio. ${ }^{1}$

b) La tendencia a conquistar el mismo nivel de autonomía por parte de otras regiones, ansiosas de equipararse en casi todo (selecciones deportivas incluidas) a Cataluña o el País Vasco, contribuía a restar valor, calidad diferencial si se quiere, al hecho de que para los nacionalistas periféricos sus territorios fuesen naciones, y no regiones de otra nación (España/Castilla). Por otro lado, también consideraban que el tiempo de los pactos de la Transición ya había pasado, que la plena incorporación de España al espacio europeo y la desaparición del Ejército como poder político fáctico permitía poner sobre el tapete cuestiones que era impensable plantear abiertamente en 1978, y que por lo tanto la soberanía de las naciones periféricas no tenía por qué ser un tema tabú. Una nueva gene-

1 Cf. Baròmetre d'Opinió Política, 19. $1^{\text {a }}$ onada 2010, febrero de 2010, del Centre d'Estudis d'Opinió de la Generalitat de Catalunya (disponible en: http://ceo.gencat.cat/ ceop/AppJa- va/pages/home/fitxaEstudi.html?colId=2488\&lastTitle=Bar\%F2metre+d\% 27Opini\%F3+Pol\%EDtica+\%28BOP\%29.+Febrer+2010), 
ración de líderes nacionalistas que surge a fines de la década de 1990 y que no habían participado del llamado «espíritu de la Transición» eran de la opinión de que ahora urgía «jubilar la Transición» (Carod-Rovira, 1998; Ollora, 1996) y de que era necesario un nuevo paso adelante. Esa nueva frontera residiría, bien en la cuasi-independencia, a menudo denominada soberanismo (según el modelo de Québec); bien la plena independencia dentro de Europa -al estilo del Scottish National Party-, o bien un estatus de plena soberanía, más o menos compartida con el Estado central y con la Unión Europea. Por tanto, no se trata ya de negociar la obtención de más competencias o incluso de más capacidad recaudatoria para la propia nación dentro del sistema autonómico; sino de reivindicar y conseguir la plena soberanía para después cederla o compartirla con otras instancias.

Esta última escalada de la reivindicación nacionalista puede verse sin duda como una posición de fuerza de los nacionalismos subestatales, acumulada tras dos décadas de ejercicio del poder y de la hegemonía cultural en sus respectivos territorios, en particular Cataluña y el País Vasco. Pero también puede interpretarse como una paradójica muestra de sus contradicciones o limitaciones sociales. Pues los sondeos de opinión, y la propia evolución de los resultados electorales en Euskadi, Cataluña o Galicia, no muestran que haya aumentado sustancialmente el porcentaje de nacionalistas, y de partidarios de la plena independencia. Más bien, lo que sucede es que los nacionalistas subestatales han radicalizado parte de sus postulados estratégicos y reivindicaciones políticas: el nuevo salto adelante en materia de autogobierno, se supone, habrá de servir para hacer avanzar sus proyectos de construcción nacional, una vez que han comprobado que las cotas de autogobierno que posibilitaba el sistema de las autonomías, y los resortes de políticas públicas que estaban a su disposición para moldear la identidad nacional de los ciudadanos, no han dado los resultados esperados.

c) Al mismo tiempo, sin embargo, una condición esencial para el avance de los proyectos nacionalistas subestatales es su transformación en modelos de nación cívica e inclusiva, capaz de asumir en su seno ciudadanos de diferentes culturas y procedencias, y de coexistir al mismo tiempo con una pluralidad de identidades compartidas. A pesar de los estereotipos negativos asociados a los nacionalismos periféricos que predominan en buena parte de la opinión pública española, el etnicismo excluyente, incluso dentro del nacionalismo vasco, no es la nota dominante en sus discursos nacionalistas subestatales, aun cuando todos ellos otorguen gran relevancia a la lengua y la cultura como marcadores fundamentales de la nacionalidad. Por el contrario, el camino de su hegemonía social pasa por el pragmatismo, por elaborar proyectos inclusivos y basados en 
el «nacionalismo del bienestar», que demuestre a sus conciudadanos de los beneficios del autogobierno y se dote de la capacidad de gestionar de modo abierto sociedades plurales y de sentimientos identitarios complejos (López Bofill, 2005; López Tena, 2009). No obstante, todavía persisten sectores significativos dentro de esos mismos movimientos nacionalistas que conciben a sus naciones como comunidades políticas definidas ante todo en términos estrictamente culturales y lingüísticos, y que mantienen dudas importantes respecto a la aceptación de la ciudadanía, del ius solis, como único criterio, o al menos como el más importante, de adscripción nacional. En parte porque privar a un movimiento nacionalista de factores de apelación emocional a sus partidarios (lengua, cultura, historia...) supone restarle capacidad movilizadora, y en parte también porque buena parte de los nacionalismos subestatales parten de una premisa: que su identidad frágil dentro de un Estado dominado por otra nación corre peligro de desaparecer (Nagel, 2005; Núñez Seixas, 2008).

4. Desde mediados de la década de 1990 se ha asistido a un resurgimiento y a una rearticulación discursiva y en parte simbólica del nacionalismo español. No es que el nacionalismo español hubiese desaparecido desde la Transición, como muchos irreflexivamente han supuesto. La ausencia del nombre no suponía la inexistencia del sujeto. Pero el nacionalismo o patriotismo español ciertamente padecía de un severo déficit de legitimación a la hora de expresarse como discurso público, tanto en el ámbito político como en el cultural e identitario, lo que no solamente afectaba a la izquierda antifranquista, sino también a la nueva derecha reformista (Sánchez Cornejo, 2009). Y, por tanto, corría el peligro de ser identificado de modo automático con la nostalgia del franquismo y con el discurso nacionalcatólico del régimen anterior. Sin embargo, el resurgimiento, o si se quiere la nueva visibilidad del discurso patriótico (o nacionalista) español no ha sido uniforme. Se ha combinado con diversos credos políticos, tanto en la derecha como en la izquierda del espectro político (Balfour/Quiroga, 2007; Núñez Seixas, 2010):

4.1. A la izquierda, esa recomposición tuvo lugar mediante la formulación en los años ochenta de una concepción que definía a España, de un modo confuso, como «nación de naciones», en la que coexistiría una nación política y varias naciones culturales, adaptación forzada de la distinción de Friedrich Meinecke (1907) entre Staatsnation y Kulturnation, pero en la que sólo la nación política sería realmente nación, es decir, sería titular de la soberanía. Ello se unía a una serie de ideas-fuerza que fueron enfatizadas durante la década socialista: europeismo y progreso frente a introspección, atraso y localismo. Después vino (a partir de principios de la década de 1990) la adaptación del discurso del patriotismo constitucional, tras una conferencia de Jürgen Habermas en Madrid, pero en el 
caso español el énfasis era situado más en la Constitución en sí, y su literalidad, que en los valores universales por ella encarnados; y se olvidaba que la propia Constitución establece taxativamente que la nación (España) existe antes de la propia Carta Magna, como hecho previo a la misma. España, su historia, lengua y cultura, eran considerados hechos irrefutables y anteriores a la Constitución, y por tanto en referentes de legitimidad de la existencia de España como nación. Desde comienzos del siglo XXI, y particularmente bajo la égida de Rodríguez Zapatero, el PSOE ha encarnado su proyecto patriótico en la «España plural», suerte de condensación del patriotismo constitucional y de la combinación de nación política y cultural, unida a una interpretación de la Historia de España que ve en la pluralidad etnocultural un valor positivo y enriquecedor; pero que sigue considerando que sólo una nación (España) es sujeto de la soberanía, aunque puedan existir a su lado entidades subnacionales específicas y se diluyan en un vocabulario confusamente postnacional las fronteras entre unas y otras, presentándose como una forma de superación de las rigideces del concepto clásico de nación (Domínguez García, 2006). Desde 2008, por lo demás, el énfasis en la España plural se ha rebajado en beneficio de la España «unida y diversa», según expresaba el presidente Rodríguez Zapatero en su discurso de investidura en abril de 2008.

Dentro de la izquierda española, además, siguen conviviendo diversas posiciones en lo relativo a la cuestión nacional. Por un lado, las favorables a un amplio reconocimiento del carácter plurinacional del Estado, compatible con la unidad del mismo y su transformación en una suerte de Estado federal asimétrico (posición encarnada por el PSC catalán y algunos sectores del PSdG gallego, pero también del socialismo valenciano, balear o vasco), en el que España, sin embargo, es algo más que un Estado compuesto de varias naciones. Es una «España común, pero no única», en la que conviven «identidades diferentes» con un «proyecto compartido» y asumido, según definición del presidente socialista de la Generalitat de Cataluña entre 2003 y 2006, Pasqual Maragall. El «federalismo plurinacional» postulado por organizaciones como Izquierda Unida (IU) incide en parecidas ideas, pero con más radicalidad en la afirmación del derecho de autodeterminación de todas y cada una de las Comunidades Autónomas, que podrían optar por la separación o por la incorporación voluntaria a un Estado federal tendencialmente simétrico (Pastor Verdú, 2007). Por otro lado, también se registran en la izquierda española voces que opinan que no es prudente debilitar en exceso el Estado central, para no poner en peligro la capacidad interventora del sector público como corrector de desigualdades sociales y territoriales. Y que, además de recordar que la personalidad nacional de España es un hecho indiscutible y basado en una Historia y cultura comunes, ven en toda cesión a las 
reivindicaciones de los nacionalismos periféricos una amenaza a la igualdad de oportunidades entre los ciudadanos de los diversos territorios del Estado.

4.2. En el ámbito de la derecha española, algunos de los postulados del neopatriotismo conservador articulado desde la década de 1980 se han aproximado a los defendidos por la izquierda, como veremos (Núñez Seixas, 2005a). Con todo, hay importantes diferencias, pese a utilizar en ocasiones una terminología bastante similar. Sobre todo, que la existencia de España como única nación se justifica de modo inalterable en la Historia, la lengua y la cultura comunes, de acuerdo con una interpretación del pasado español que todavía presenta bastantes resabios de la visión nacional-católica de la Historia de España, y cuya época de esplendor siguen siendo los Austrias, la conquista de América y, eso sí, la aprobación de la Constitución de 1812. Sin embargo, entre esta fecha y 1978 se abriría un largo paréntesis de inestabilidad y excepcionalidad trágica, que cabría olvidar (guerra civil incluida) en beneficio de la estabilidad nacional. La Constitución de 1978 y el Estado de las Autonomías son ensalzados, ahora, como un logro colectivo, y como un lugar de memoria en sí, incapaz de ser reformado o tocado salvo en aspectos técnicos y secundarios. El franquismo habría sido un accidente en la Historia patria, y lo mejor sería respetar el pacto de olvido de la Transición.

La batalla por la relegitimación del discurso patriótico de la derecha conservadora española se ha librado en dos frentes. Uno, la apropiación del término «patriotismo constitucional», patente desde el 2002, pero con una adecuada justificación historicista de la nación española. Otro, patente en algunas secciones territoriales de AP y luego del PP desde mediados de la década de 1980, fue la adopción de un mensaje regionalista moderado, que permitió a la derecha española el aceptar plenamente el Estado de las Autonomías, incluida la definición de «nacionalidad histórica». Con todo, el Estado autonómico actual es considerado como el sistema ideal, que ha de tender hacia una homogeneización y nivelación de techos competenciales en lo posible entre todas las Comunidades Autónomas, y que sólo ha de ser reformado en aspectos secundarios y meramente funcionales o técnicos.

Sin embargo, el esfuerzo por actualizar y relegitimar el discurso patriótico conservador, patente sobre todo durante la primera etapa del gobierno Aznar (1996-2000), necesitado de los apoyos parlamentarios de los nacionalistas catalanes y vascos, fue acompañado en su segunda etapa por una ofensiva encaminada a la renacionalización de España, en la que adquirieron un papel preponderante la apuesta por la revisión de la Historia, y en particular de la Historia reciente, según moldes muy cercanos al discurso historiográfico franquista; el énfasis en los símbolos comunes y su exaltación y difusión (desde la bandera 
bicolor al himno); y la deslegitimación generalizada de los nacionalismos periféricos, para lo que la lucha antiterrorista ofrecía un repertorio argumental complementario, ampliamente desplegado desde diversos medios de comunicación. La oposición frontal del PP a los procesos de reforma de los Estatutos de Autonomía iniciada bajo el gobierno Zapatero, y sus reticencias frente a los procesos de paz abiertos en el País Vasco tras las treguas declaradas por ETA en marzo de 2006 y septiembre de 2010, así como su negativa a apoyar la Ley de Memoria Histórica impulsada por el Gobierno del PSOE, son nuevas piedras de toque que muestran cómo el discurso patriótico conservador se ha retroalimentado una vez más con un fuerte componente reactivo, y con un retorno a la revisión del pasado, que han invalidado en buena parte los intentos de reconstrucción discursiva anteriores.

La rearticulación del discurso de la derecha conservadora, dispuesta a asumir su condición de tal «sin complejos», ha ido acompañada de la construcción de un potente aparato mediático (Muñoz Soro, 2007). No sólo la defensa de la integridad de España como nación, y el uso exclusivo de tal concepto para España, se eleva a bandera de combate que, se supone, atraerá votos en toda España menos en las periferias nacionalistas. También se renuncia definitivamente a todo intento de construir una suerte de «consenso antifascista» que sirva de discurso legitimador de un patriotismo democrático compartido con la izquierda de referente español. Y en los últimos tiempos se ha abierto una tendencia a favorecer la reasunción de competencias por parte del Estado central, a reforzar sus atribuciones y frenar los «excesos» del sistema autonómico.

Tampoco es nada nuevo. El nacionalismo español, particularmente su tendencia católico-tradicionalista y conservadora, pero también el de orientación liberal, se ha definido desde la conclusión de la guerra colonial de 1898, de modo preferente, frente a un enemigo interno: los nacionalismos subestatales. Pero esa relación de oposición incluye igualmente una dinámica de retroalimentación con puntos de contacto. Pues entre el nacionalismo español y los nacionalismos vasco, catalán y gallego también han circulado imágenes y modelos comunes, a menudo con moldes invertidos. Y la evolución teórica y simbólica de un polo también condiciona, como en un juego de espejos, la evolución del contrario. Una paradoja es que ambos polos pretendan la sacralización de la propia identidad mientras, al mismo tiempo, denuncian la sacralización de la contraria. Si todos los nacionalismos han de ser cívicos y basarse en la voluntad de la mayoría como criterio más eficaz y democrático de legitimación de la comunidad política, esto rige para todos por igual. Pero este postulado no es aceptado por todos los nacionalistas, de Estado o sin Estado. 


\section{DeLENDA EST Hispania?}

Concluyamos con cuatro observaciones finales, que son de pertinente aplicación a la evolución de la cuestión territorial en el Estado español en los últimos seis años (2004-2010), coincidiendo con el período de Gobierno del PSOE en minoría parlamentaria, y con particular protagonismo durante su primera legislatura (2004-2008) de los partidos nacionalistas (ERC, BNG, CiU, PNV y otros) que le otorgaron su apoyo para sacar adelante leyes y presupuestos:

1. De entrada, nos encontramos ante un debate preponderantemente nominativo: qué territorio es la nación. Y qué significa ser nación. Para muchos, España va camino de desaparecer como única nación y de convertirse en un mero agregado de naciones diversas. Ni tanto, ni tan calvo. Pues el ruido en este aspecto ha sido y es mucho mayor que las nueces. Y las novedades conceptuales son mínimas. España sigue sin ser reconocida como Estado plurinacional en términos normativos. Y Cataluña (ni Euskadi, ni Galicia), por ahora, tampoco. Siguen siendo nacionalidades en los términos que estableció la Constitución de 1978, es decir, realidades culturales e históricas, pero desprovistas de soberanía. Aunque el anteproyecto de Estatuto de Autonomía de Cataluña, aprobado por el Parlamento catalán a comienzos de 2006, incluía en su preámbulo la definición de Cataluña como nación, algo inaceptable para el Gobierno central, las largas negociaciones en Madrid y el acuerdo por sorpresa entre Rodríguez Zapatero y el líder de CiU, Artur Mas, desbloquearon la cuestión mediante su reducción a un silogismo conceptual. Pues aunque también se recoge la definición de Cataluña como nación en el preámbulo del Estatuto de Autonomía finalmente aprobado en las Cortes de Madrid, en mayo de 2006, y refrendado por el 80\% de los votantes catalanes en junio, los términos de tal reconocimiento son políticamente inocuos, en la medida en que el texto definitivo establece explícitamente que tal reconocimiento nacional de Cataluña tiene lugar dentro de los parámetros ya establecidos para las nacionalidades en la Constitución de 1978: nación es igual a nacionalidad. A pesar de ello, como es sabido, el Tribunal Constitucional derogó varias de las concesiones más simbólicas a la plurinacionalidad recogidas en el texto del Estatut, y en el paisaje político de Cataluña ha irrumpido con cierta fuerza una percepción social compartida por significativos sectores sociales de distanciamiento o extrañamiento de España, cuya plasmación política es todavía inestable (Casals, 2010).

Por otro lado, el futuro de la negociación política que, previsiblemente, pondrá fin a la violencia terrorista en el País Vasco pasará, probablemente, por un acuerdo de calado similar, si bien en ese caso la mayor presencia social y política del independentismo, así como el énfasis en la territorialidad (incluyendo Navarra y hasta los territorios vascos de Francia) por parte de la izquierda nacio- 
nalista hace mucho más complejo el llegar a ese punto. Pero la reivindicación independentista tampoco desaparecerá. Igualmente complejo, en este caso por la menor fuerza social del nacionalismo gallego, será el proceso en Galicia, donde el diapasón a imitar será el marcado por Cataluña.

España, pues, seguirá siendo, como en su día resumió de forma magistral el politólogo Juan Linz (1993), un ejemplo paradójico de fracaso de los nacionalismos, tanto del nacionalismo de Estado (el español) como de los nacionalismos subestatales. Ninguno de ellos parece capaz de imponer su hegemonía social, política y cultural de modo indiscutido sobre sus territorios de referencia. La suerte de empate, en términos futbolísticos, que persiste entre nacionalismo español y nacionalismos periféricos está llamado a perdurar en los lustros venideros. Del mismo modo, dentro de la dinámica creada por el Estado de las Autonomías, seguirá presente la tensión entre simetría y asimetría de niveles de autogobierno entre las 17 Comunidades Autónomas. Cada vez que Cataluña o el País Vasco obtengan cuotas mayores de autogobierno, todas las demás autonomías tenderán a presionar para adquirir un nivel semejante, y en ello coincidirán las elites más o menos regionalistas locales de todos los partidos. Al final, las «nacionalidades históricas» darán comienzo a otra carrera por la consecución de un estatus diferencial, o de soberanía, para diferenciarse también del resto de «regiones» que son definidas como partes de otra nación (España, o Castilla). Y a ello se unirá el hecho de que, para la mayor parte de los ciudadanos españoles, incluyendo a porcentajes muy significativos de los que habitan en las periferias con presencia de nacionalismos subestatales, España sigue siendo una nación. Y, como tal, no debe tolerar la fragmentación de su soberanía. Un Estado socialmente plurinacional, ma non troppo. Y, como mucho, un Estado pseudoplurinacional desde el punto de vista jurídico-normativo, pero no en los aspectos fundamentales de su definición y arquitectura simbólica.

2. La razón de esta complejidad es simple. España no es un Estado plurinacional en sentido estricto. Tampoco es un Estado nacional. Es algo intermedio. Las identidades nacionales, colectivas y territoriales en general, presentan dinámicas que no siempre se corresponden con aquello que creen, o quieren hacer creer, las elites políticas. Ni siquiera la presencia en un territorio determinado de etnicidades diversas, de lenguas diferentes y de culturas en sentido amplio es fundamento suficiente por sí solo para favorecer el reforzamiento de una conciencia nacional exclusiva o excluyente de otras esferas de identificación. Esto es aún más patente en sociedades capitalistas avanzadas donde, a diferencia de lo ocurrido en el antiguo bloque soviético en 1989-1991, no se asistió a una quiebra generalizada de un sistema social y de valores, certidumbres y criterios de legitimidad política. Existe en el caso español una suerte de equilibrio más 
o menos inestable entre los niveles sociales de conciencia regional o nacional periférica y la conciencia nacional española en el conjunto de la población, y siguen siendo mayoría quienes se sienten españoles y vascos, catalanes, gallegos, etcétera, aunque es cierto que en el País Vasco los índices de polarización en los sentimientos de identidad nacional (entre el polo de «sólo vasco» y el de «sólo español») son mayores que en otras comunidades autónomas (CIS, 2006). Por expresarlo de otro modo: los nacionalismos vasco y catalán, por ejemplo, no disfrutan de una hegemonía social incontestable en sus territorios de referencia, sino más bien relativa. Apenas un 50\% de los votos en las elecciones, y eso con grandes variaciones entre los resultados electorales en comicios autonómicos y en elecciones generales, pues en estas últimas los partidos «españoles», aunque posean sucursales o incluso variantes autónomas, como el PSC catalán, siguen obteniendo ventaja, en comicios que además presentan mayores cotas de participación.

Por otro lado, si no se produce una crisis repentina de legitimación del sistema político, es difícil que la cuestión territorial/nacional aparezca en el primer plano de las prioridades de los ciudadanos, incluso de los que residen en las «nacionalidades históricas». Si un ejemplo fue el protagonismo adquirido por la cuestión nacional en Europa oriental tras la caída del Muro de Berlín, también lo fue en el sentido contrario el fracaso del referéndum de secesión de Quebec en el otoño de 1995, y la pérdida de apoyo desde entonces al proyecto independentista quebequés. La autodeterminación es un derecho cuyo ejercicio presenta mayores complejidades que su formulación teórica. Por ejemplo: ¿cómo definir el sujeto? ¿Cuántas opciones se deben presentar a los ciudadanos, y de qué manera? ¿Acaso los ciudadanos no tienen derecho, también, a no elegir entre identidades compartidas? Quizás el ejemplo máximo de esa ambigüedad es el fracaso sucesivo de los varios referéndums celebrados en el Estado libre asociado de Puerto Rico. Y precisamente por la conciencia de su sólo relativa fuerza, los sectores independentistas de los nacionalismos periféricos han tendido a optar hasta, al menos, 2007-2008, por fórmulas elusivas del derecho de autodeterminación, por la consecución de etapas intermedias y/o por la redefinición del derecho de autodeterminación como una suerte de proceso largo y sucesivo hacia la emancipación nacional, ejercido a través del gradualismo pragmático, y su reconocimiento jurídico en el ordenamiento legal español.

3. Las identidades compartidas pueden ser mayoritarias en el territorio español. Y el nivel de conflicto intergrupal entre diferentes regiones y comunidades es muy bajo en el nivel de la interacción cotidiana (Sangrador, 1996). Pero es un hecho evidente que la identidad nacional española sigue sufriendo de problemas de legitimación simbólica. Ni la bandera ni el himno, pongamos por caso, han 
conseguido suscitar hasta fechas recientes una adhesión sentimental semejante a la que despiertan en otros países, si bien la recuperación del prestigio exterior y la autoestima de la identidad española es un proceso constatable desde fines del siglo XX (Jáuregui/Ruiz Jiménez, 2005; Muñoz Mendoza, 2009). Los símbolos informales, creados en parte por la sociedad de la información y la generalización de modelos de consumo cultural masivo, operan de modo más eficaz. Ahí están: desde los héroes deportivos, llámense Fernando Alonso, Rafael Nadal o la selección española de fútbol, a los cantantes de moda que expresan la canción española en sus diversas tonalidades. Son las formas de socialización de una identidad nacional que algunos autores, como Michael Billig (1995), han denominado nacionalismo trivial, pero cuya relevancia en sociedades posmodernas y crecientemente globalizadas no es desdeñable. Existe pues un extendido sentimiento, también en las periferias, de pertenencia a una nación española, como comunidad de cultura, de referentes cotidianos y de experiencia vital. Otra cosa es que no siempre sepamos cómo medir ese sentimiento de modo fehaciente.

4. Finalmente, quizás el nuevo debate sobre la cuestión territorial aparecerá a ojos de las nuevas generaciones como una cuestión caduca en pocos años. Más que un nuevo debate, será casi un debate del pasado, casi vetusto, al menos en sus términos clásicos. Pues España se ha transformado en pocos años en un país de inmigración masiva, procedente de África, Latinoamérica y Europa oriental. Y con ello la faz de la sociedad española ha sufrido cambios poco menos que espectaculares, aunque por ahora se han restringido a las principales áreas (Madrid, Cataluña, Levante) en las que se concentran los recién llegados.

¿Qué consecuencias tendrá este hecho para la evolución de la cuestión territorial o nacional? Es pronto para augurarlo. Quizás en quince años los debates sobre autogobierno territorial parecerán caducos ante el nuevo desafío, que no será otro que la construcción de un modelo de integración y multiculturalismo adaptado a las necesidades del país y los propios valores sentidos como definidores de su identidad colectiva por la mayoría de los ciudadanos españoles (Kleiner-Liebau, 2009). ¿Será válido ese modelo para todos los territorios? Tal vez. Por un lado, la inmigración es considerada por buena parte del pensamiento patriótico conservador español, pero también por algunos sectores de los nacionalismos periféricos, como una seria amenaza para la cohesión social y cultural de sus patrias. Por otro lado, las posiciones más aperturistas dentro de los nacionalismos subestatales, que aspiran a construir sus propias sociedades multiculturales, tampoco disimulan el temor a que esa nueva inmigración suponga una amenaza definitiva para la supervivencia de sus lenguas y culturas específicas, del mismo modo que el nacionalismo quebequés reaccionó con temor en su momento ante la llegada de inmigrantes más interesados en aprender inglés que 
francés (Zapata-Barrero, 2009). Por decirlo de manera simple: ¿Hablarán los inmigrantes magrebíes o pakistaníes euskera, catalán o gallego? ¿Cómo integrar sus lenguas y culturas en imaginarios culturales y simbólicos que todavía padecen de una fuerte impronta romántico-historicista?

Todo apunta a que los nacionalismos subestatales aún no han acabado de definir sus modelos de convivencia multicultural para el largo siglo XXI. Tampoco lo han hecho los nacionalismos de Estado, empezando por el nacionalismo español. Quizás porque el molde del nacionalismo clásico ya no es suficiente para encajar sociedades de pertenencias identitarias múltiples. Pero, hasta ahora, todos los intentos por reinventar el nacionalismo han acabado en el fracaso o la indiferencia. Una España postnacional (Resina, 2002) está aún por inventar. Una Cataluña, Euskadi o Galicia postnacionales, también.

\section{REFERENCIAS BIBLIOGRÁFICAS}

AJA, E. (1999), El Estado Autonómico: Federalismo y hechos diferenciales, Madrid, Alianza.

Balfour, S., y Quiroga, A. (2007), España reinventada, Barcelona: Península.

BASTiDA, X. (1998), La nación española y el nacionalismo constitucional, Barcelona, Ariel.

Beramendi, P., y Máız, R. (2003), «Federalismo y multinacionalidad: un análisis institucional del Estado de las Autonomías», Zona Abierta, 104-105, pp. 191231.

Billig, M. (1995), Banal Nationalism, Londres, Sage.

CAROd-Rovira, J. Ll. (1998), Jubilar la transició. Una proposta nova per al segle XXI, Barcelona, Columna.

Casals, X. (2010), El oasis catalán (1975-2010). ¿Espejismo o realidad?, Barcelona, Edhasa.

Centro De Investigaciones Sociológicas [CIS] (2006), CIS, Estudio 2610, Barómetro autonómico, disponible en: http://www.cis.es/cis/opencms/-Archivos/ Marginales/2600_2619/2610/Es2610.

Domínguez García, F. (2006), Más allá de la nación. La idea de España como «Nación de naciones», Barcelona, Fundació Rafael Campalans.

García Álvarez, J. (2002), Provincias, regiones y comunidades autónomas. La formación del mapa político de España, Madrid, Temas del Senado.

GENIEYs, W. (1997), Les élites espagnoles face à l'État. Changements de régimes poli- 
tiques et dynamiques centre-périphéries, París, Montréal, L'Harmattan.

Jáuregui, P., y Ruiz Jiménez, A. M. ${ }^{a}$ (2005), «A European Spain: The recovery of Spanish self-esteem and international prestige», en Iсніл, A. у Spoнn, W. (eds.), Entangled Identities: Nations and Europe, Londres, Ashgate, pp. 55-71.

Kleiner-Liebau, D. (2009), Migration and the Construction of National Identity in Spain, Frankfurt a. M.,Madrid, Vervuert, Iberoamericana.

Kraus, P. A. (1996), Nationalismus und Demokratie. Politik im spanischen Staat der Autonomen Gemeinschaften, Wiesbaden, Deutscher UniversitätsVerlag.

Linz, J. J. (1993), «Los nacionalismos en España: una perspectiva comparativa», en Aura E. d' y Casassas, J. (eds.), El Estado moderno en Italia y España, Barcelona, CNRS, Universitat de Barcelona, pp.79-87.

López Bofill, H. (2005), La independència i la realitat: Bases polítiques, jurídiques i socials per a la sobirania de Catalunya, Palma de Mallorca, Moll.

López-Tena, A. (2009), Cataluña bajo España: La opresión nacional en democracia, Barcelona, Dèria.

Moral, F. (1998), Identidad regional y nacionalismo en la España de las Autonomías, Madrid, CIS.

Moreno, L. (1997), La Federalización de España, Madrid, Siglo XXI.

Mota-Consejero, F. (1998), Cultura Política y opinión pública en las Comunidades Autónomas: un examen del sistema político autonómico en España 1984-1996, Barcelona, ICPS, Working Paper, n. ${ }^{\circ} 153$. -, (2008), Capital social y gobernabilidad. El rendimiento político de las Comunidades Autónomas, Madrid, CEPC.

Muñoz Mendoza, J. (2009), «From National-Catholicism to Democratic Patriotism? Democratization and Reconstruction of National Pride: The case of Spain (1981-2000)», Ethnic and Racial Studies, 32: 4, pp. 616-639.

Muñoz Soro, J. (2007), «Sin complejos: Las nuevas derechas españolas y sus intelectuales», Historia y Política, 18, pp. 129-164.

NageL, K.-J. (2005), «Dilemmas of stateless nations in the European Union», en Márz, R., y Requejo, F. (eds.), Democracy, Nationalism and Multiculturalism, Londres, Nueva York, Frank Cass, pp. 127-143, 2005.

NúÑez SeIXAs, X. M. (2005a), «From National-Catholic Nostalgia to "Constitutional Patriotism": Conservative Spanish Nationalism since the early 1990s», en BALFour, S. (ed.), The Politics of Contemporary Spain, Londres, Routledge, pp. 121-45. - , (2005b), «Regions, nations and nationalities: On the Process of Territorial Identity-Building During Spain's Democratic Transition and Consolidation», en

Pasado y Memoria. Revista de Historia Contemporánea, 9, 2010, pp 129-148 
Waisman, C. H. y ReIn, R. (eds.), Spanish and Latin American Transitions to Democracy, Brighton, Portland, Sussex Academic Press, pp. 55-79.

—, (2008), «Los nacionalismos subestatales, la unificación europea y el mito de la soberanía. Algunas reflexiones», Revista Internacional de Filosofía Política, 31, pp. 179-197.

-, (2010), Patriotas y demócratas. El discurso nacionalista español después de Franco, Madrid, Los Libros de la Catarata.

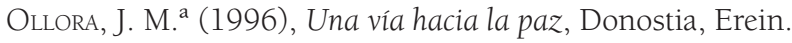

Pastor Verdú, J. (2007), «La izquierda de ámbito estatal. Entre el "patriotismo constitucional" español y el federalismo plurinacional», en TAibo, C. (ed.), Nacionalismo español. Esencias, memorias e instituciones, Madrid, Los Libros de la Catarata, pp. 193-212.

Quintana Garrido, X. R. (2010), Un longo e tortuoso camiño. Adaptación, crise e cambio no BNG, 1971-2009, Vigo, Galaxia.

Resina, J.-R. (2002), «Postnational Spain? Post-Spanish Spain?», Nations and Nationalism, 8:3, pp. 377-396.

Sánchez Cornejo, D. (2009), «La Unión de Centro Democrático y la idea de España: La problemática reelaboración de un discurso nacionalista para un contexto democrático», Historia del Presente, 13, pp. 7-20.

SAngrador García, J. L. (1996), Identidades, actitudes y estereotipos en la España de las autonomías, Madrid, CIS.

SolÉ TuRA, J. (1985), Nacionalidades y nacionalismos en España, Madrid, Alianza.

Zapata-Barrero, R., ed. (2009), Immigration and Selfgovernment of Minority Nations, Bruselas, Peter Lang. 